POLLACK PERIODICA

An International Journal for Engineering and Information Sciences

DOI: $10.1556 / 606.2017 .12 .2 .6$

Vol. 12, No. 2, pp. 67-78 (2017)

www.akademiai.com

\title{
TRAFFIC PERFORMANCE OF SIGNALIZED CIRCULAR INTERSECTIONS
}

\author{
${ }^{1}$ Szabolcs BARNA, ${ }^{2}$ Gábor SCHUCHMANN \\ Department of Highway and Railway Engineering, Faculty of Civil Engineering, \\ Budapest University of Technology and Economics, Müegyetem rkp. 3., H-1111 Budapest, \\ Hungary, e-mail: ${ }^{1}$ barna.szabolcs@epito.bme.hu, ${ }^{2}$ schuchmann.gabor@epito.bme.hu
}

Received 1 January 2016; accepted 29 March 2017

\begin{abstract}
Traffic control strategies of signalized circular intersections are analyzed in this article after a brief overview of traffic lights in roundabouts. A detailed description was made on the 'direct' mode of operation of the Hungarian regulation describing three types of control program. Finally a comparison of traffic performance is given based on the main geometric features and parameters of the signal programs with a description of the signal plan structure. The PTV Vissim environment was used to examine and evaluate the performance of each combination through the average delay per vehicle resulting proposals for the application as well as for further studies in subject.
\end{abstract}

Keywords: Circular intersection, Traffic circle, Roundabout, Signal control, Simulation, PTV Vissim, Delay, Saturation flow

\section{Introduction}

\subsection{Benefits of signal control}

Although the nature and basic purpose of a roundabout contradicts almost everything signalization is all about, signalized roundabouts may handle a few situations better like higher speeds, pedestrian crossings, delays and queues. Signal control can reduce the problems of exceeding critical values of these traffic flow parameters with regulating the traffic patterns, resulting improved capacity and safety [1], [2], [3], [4]. 


\subsection{Applications of signalized roundabouts}

After realizing that the same circle-shaped intersection equipped with traffic lights has further capacity reserves related to the roundabout, many junctions were built or rebuilt based on these harmonized traffic and geometrical features [5]. The types of signalization vary based on the control of internal (entering) and external (circulating and leaving) traffic flows, the daily time of operation and the number of approaches controlled by traffic signals [1].

\subsection{Focus}

This paper deals only with the 'direct' mode of operation as well as the Hungarian regulation does, where traffic lights are influencing all traffic entering, circulating or leaving from within the roundabout or circle [2]. The article focuses from theoretical point of big circle-shaped intersections with signal control to find the peak-hour capacity with no vehicle detection or optimization questions.

\section{Programs of direct control}

All the program parameters of the signal plans including cycle length only depend on the geometrical features of the circular intersection and not on traffic volumes. Volume values only needed for determining the total number of lanes. The Hungarian regulation contains three types of direct control programs [6], [7]:

- Leg by leg control called the turbine principle control;

- Two-phase control called opposite legs control;

- All legs control called the entire turbine principle control.

\subsection{Program of leg by leg control}

Each signal group at the incoming flows turns green one after another, clockwise and the signal groups around the circle - the signal cordons - providing a continuous traffic flow on the circular path (see Fig. 1) [5].
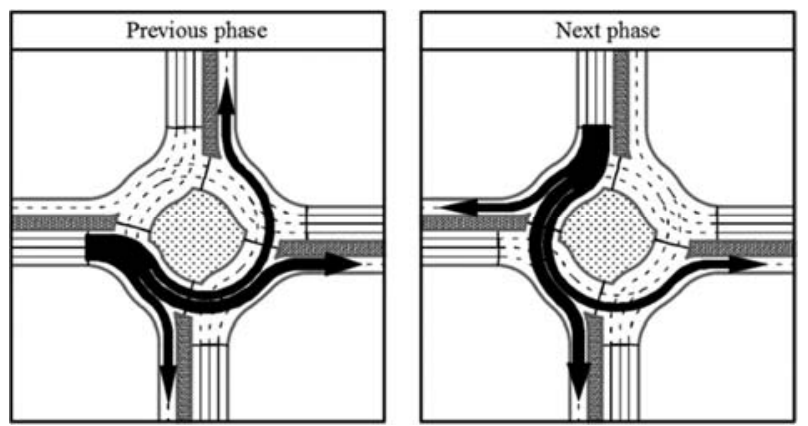

Fig. 1. Leg by leg control at signalized four-arm circular intersection 
Flexible management of asymmetrical traffic flows is an advantage, i.e. the total entry capacity can be used for the left-turning movement [8], [9]. So, there is no need for separated left-turn lanes.

The signal plan of a leg by leg control program is defined by the following four parameters shown with the program structure and the signal groups in Fig. 2, [5], [6]:

- Entering time $\left(t_{i n}\right)$ - the time for the first entering vehicle to reach the first signal cordon after the beginning of the entry green signal (e.g. between D1, C2);

- Exiting time $\left(t_{\text {out }}\right)$ - the time for the last entering vehicle pass the last signal cordon after the end of the entry green signal (e.g. between B1, D2);

- Inter-green time between the entering flow and the circle flow $\left(t_{i g 12}\right)$ - the circle flow follows the entering flow (e.g. between $\mathrm{C} 1, \mathrm{C} 2$ );

- Inter-green time between the circle flow and the entering flow $\left(t_{i g 21}\right)$ - the entering flow follows the circle flow (e.g. between D2, D1).
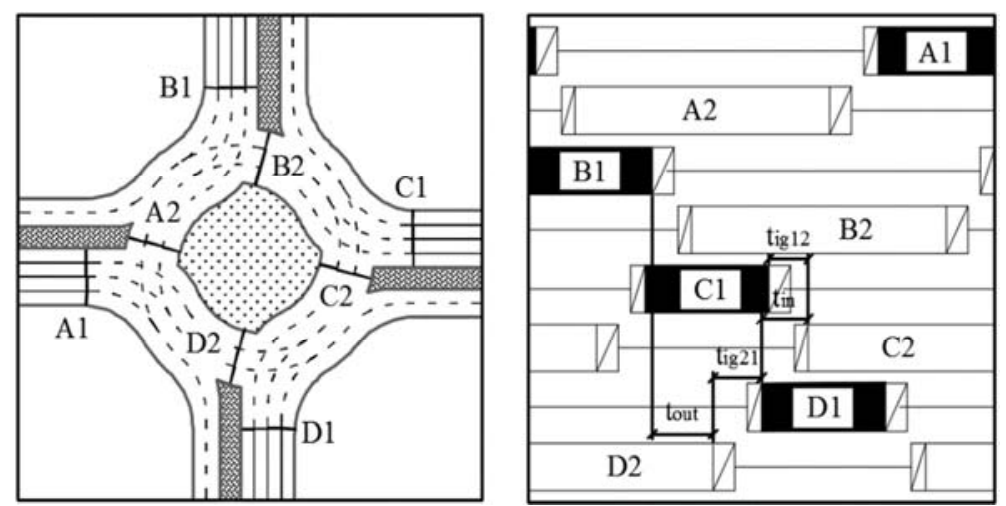

Fig. 2. Signal groups and signal plan structure - leg by leg control

\subsection{Program of two-phase control}

Two opposite traffic flows get green signal at the same time. All left-turning vehicles have to stop on the opposite side before the incoming lanes in a way; the last stopped vehicles cannot block the movement of the first leaving vehicles on the other side (see Fig. 3). The stopped vehicles leave the circle before the other two opposite traffic flows arrive. The left-turning movement's capacity is determined by storage areas around the central island and by the cycle length [6], [10], [11], [12], [13]. In this case, there is a need for separated left-turn lanes. It is possible to give more green time to the straight and right-turning movement, but it is reducing the capacity of the leftturning movement. This program fits best for four-arm intersections, but it is possible to adapt for any number of arms [14]. 

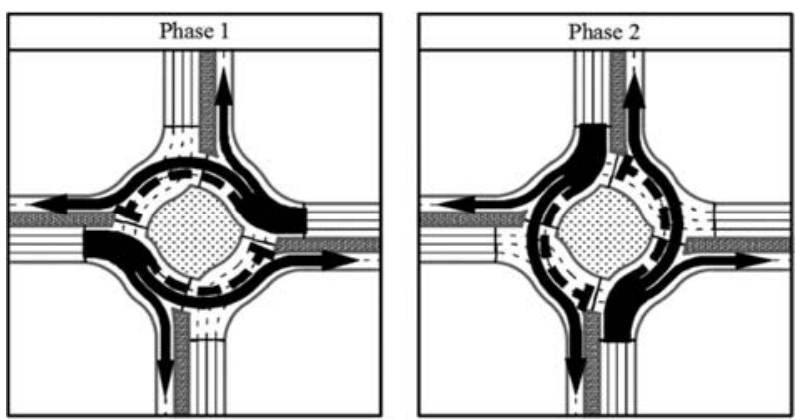

Fig. 3. Two-phase control at signalized four-arm circular intersection

This two-phase program uses main parameters and signal groups that are different from the leg by leg control (except the inter-green times) due to different operation (see Fig. 4) [10]:

- Green signal time $\left(t_{g}\right)$ - green time for left-turn movement at the entry point (determined by storage areas between the first and second signal cordon);

- Exiting time $\left(t_{\text {out }}\right)$ - the time for the last entering vehicle pass the first signal cordon after the end of the entry green signal;

- Pre-open time $\left(t_{p o}\right)$ - the time offset between the green signal of the first signal cordon (in front of the entry point) and the entry green signal (it provides the continuous flow of the traffic without stopping for the entering flow);

- Inter-green time between the entering flow and the circle flow $\left(t_{i g 12}\right)$ - the circle flow follows the entering flow;

- Inter-green time between the circle flow and the entering flow $\left(t_{i g 21}\right)$ - the entering flow follows the circle flow.
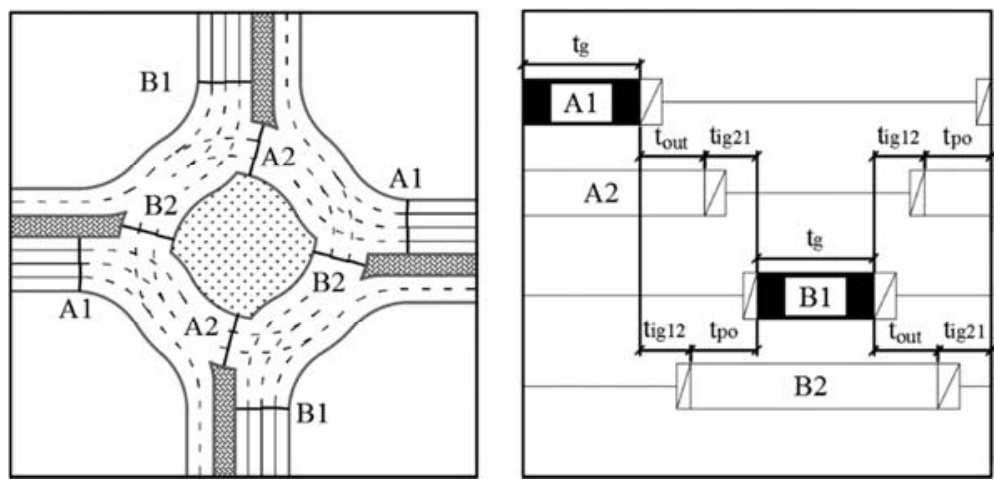

Fig. 4. Signal groups and signal plan structure - two-phase control 


\subsection{Program of all legs control}

All entering flows get green signal at the same phase. The entered vehicles stop at the first signal cordon in a way; the last stopped vehicles cannot block the first leaving vehicles on the other approaches. All stopped vehicles leave the circle at the same phase (see Fig. 5) [6], [9]. The length of the entry green signal time is determined by storage areas behind the first signal cordon. Time offsets must be applied among the green times of the circle lanes (because of the merging lanes of spiral geometry) to avoid the self-closing of the intersection. Like at the leg by leg control there is no need for separated left-turn lanes.
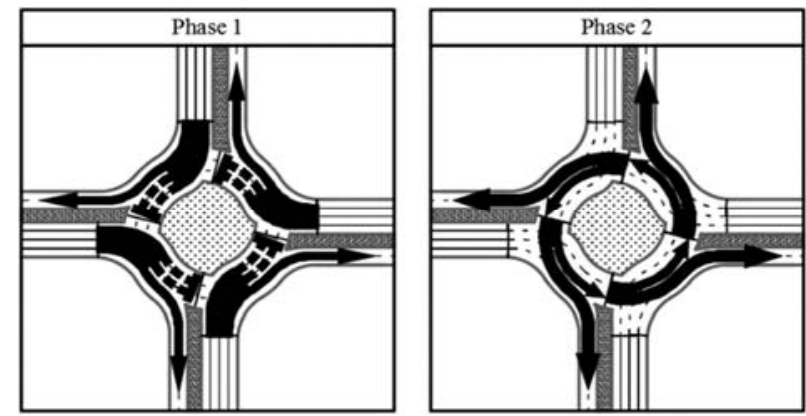

Fig. 5. All legs control at signalized four-arm circular intersection

The necessary signal groups and the signal plan made with the following parameters is shown in Fig. 6:
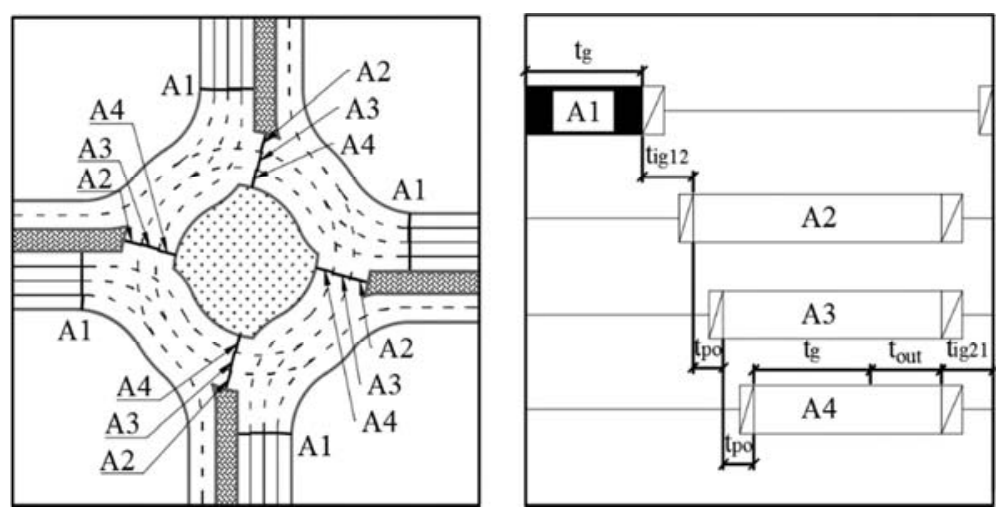

Fig. 6. Signal groups and signal plan structure - all legs control

- Green signal time $\left(t_{g}\right)$ - green time for the entering traffic flows at the first stop line (determined by storage areas behind the first signal cordon, where all vehicles stop); 
- Exiting time $\left(t_{\text {out }}\right)$ - the time run by the last left-turning vehicle between the first and the last signal cordon;

- Pre-open time $\left(t_{p o}\right)$ - the offset between the starts of the green time at the first signal cordon per merging lanes;

- Inter-green time between the entering flow and the circle flow $\left(t_{i g 12}\right)$ - the circle flow follows the entering flow;

- Inter-green time between the circle flow and the entering flow $\left(t_{i g 21}\right)$ - the entering flow follows the circle flow.

Tangential geometry design can reduce the number of time offsets and if the circle is large enough, a signal plan without time offsets can be made as well. In this case fewer vehicles are allowed to enter than the storage capacity of the areas behind the first signal cordon.

\section{Evaluation of performance}

This study is based on the examination of 10 microscopic models: two types of circular intersection five different sizes each. The geometry of the four-arm intersections based on a 'rotor' roundabout [7] (see Fig. 7) and tangential approach design was used for the five-arm intersections [11] (see Fig. 8). The models were made in a PTV VISSIM environment [15], which is a proved solution for microscopic traffic flow simulation [16], [17], [18].

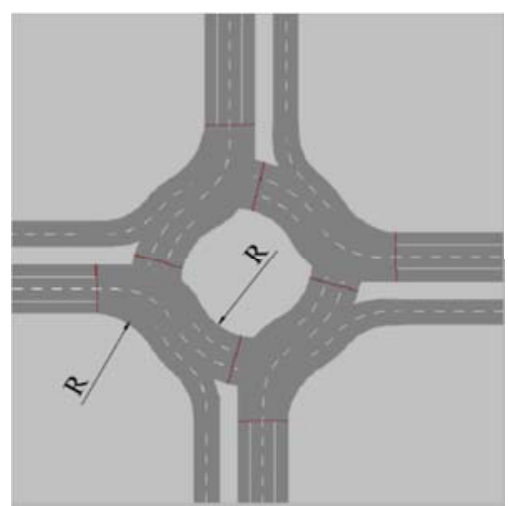

Fig. 7. Four-arm circular intersection

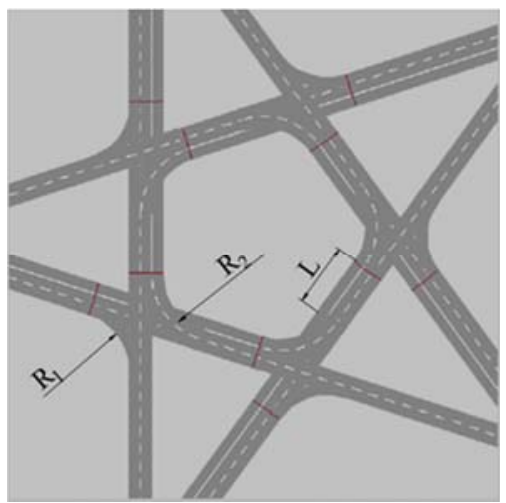

Fig. 8. Five-arm circular intersection

\subsection{Modeling}

All modeled circular intersections had symmetrical approach geometry. The fourarm intersections used four lanes (one lane for left, two lanes for straight and one lane for right movements); the five-arm roundabouts used three lanes (one lane for the left, one for the straight and one lane for the straight and right movements) both on approaches and on circulatory sections. The vehicles had to choose the proper lane before entering; means there is no lane change on the circulatory section. Width of the 
lanes were $3.75 \mathrm{~m}$ except the circulatory section of four-arm versions, where $5 \mathrm{~m}$. Radii of the four-arm geometries were $20,30,40,50,60 \mathrm{~m}$, the value of $R_{1}$ for five-arm geometries was $20 \mathrm{~m}, R_{2}$ and $L$ were 20, 30, 40, 50, $60 \mathrm{~m}$ (see Fig. 7 and Fig. 8).

All possible signal plans were made for each of the geometries resulting 30 different models to run. Only passenger cars were used in the models with the desired speed of $50 \mathrm{~km} / \mathrm{h}$ on approaches and reduce speed on circulatory sections. During the simulation, traffic volume increased continuously in every 4200 secs from a small number of vehicles as long as the congestion started (the first $600 \mathrm{sec}$ were for volume increasing and the other $3600 \mathrm{sec}$ were for evaluation). The volumes on the approaches were the same. Ratio of the flows of the left, straight and right movements were 1:2:1 for fourarm intersections and 1.5:2:1 for the five-arm intersections in every run resulting balanced lane use. Measured traffic performance parameters of the simulations with different random seeds were:

- the average delay of all vehicles [s];

- the number of passing vehicles per hour $[\mathrm{pcu} / \mathrm{h}]$.

\subsection{Expected capacity based on the signal plans}

If the central island is large enough, it can provide more green time in one cycle than the cycle time of the signal plan (see Fig. 9 and Fig. 10), because green times of the legs overlap meaning there can be more than one, even conflicting traffic flow moving within the circulatory section. This is impossible in conventional traffic intersections.

The larger the central island is, the higher the ratio of the sum of the green signal times and the cycle time meaning the capacity will be (no rounding).

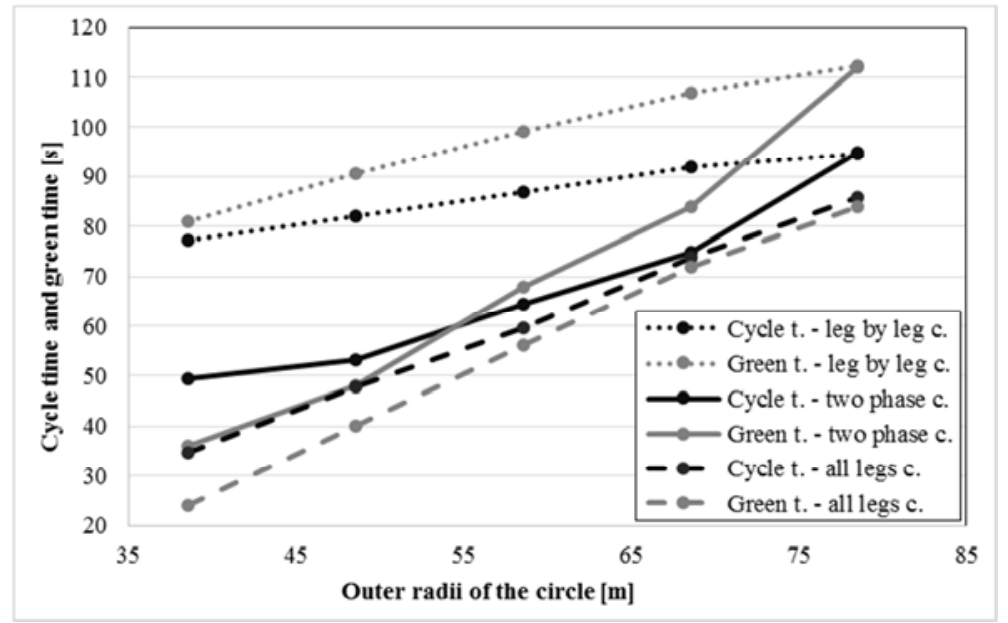

Fig. 9. The relation between the size of the circle and the cycle length/green times of the signal plan (no rounding) - four-arm circular intersections 


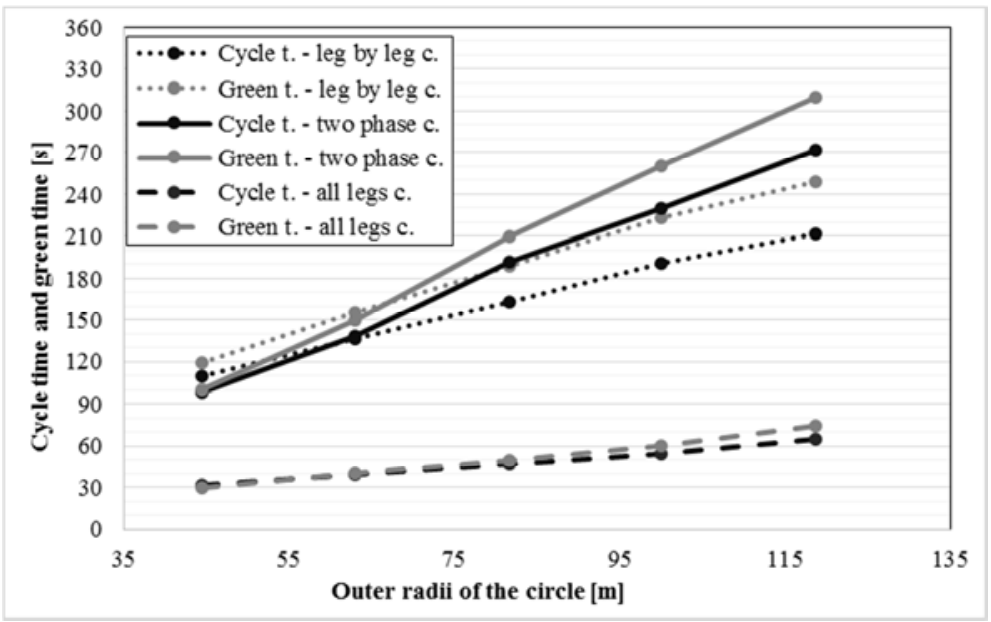

Fig. 10. The relation between the size of the circle and the cycle length/green times of the signal plan (no rounding) - five-arm circular intersections

\section{Results}

Fig. 11 to Fig. 20 present the relation between the average delay and the traffic volume in the examined circle-shaped intersections (leg by leg control - dotted lines, two phase control - dashed lines, all legs control - continuous lines).

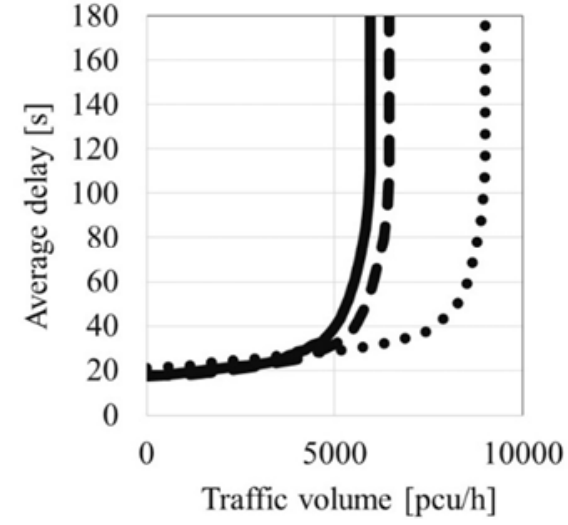

Fig. 11. Delay in four-arm circle $(\mathrm{R}=20 \mathrm{~m})$

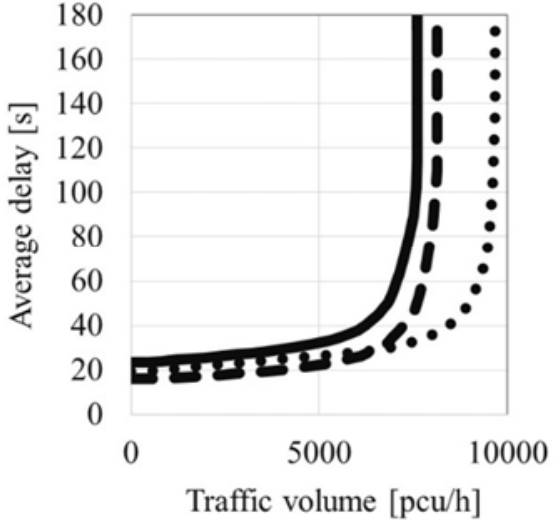

Fig. 12. Delay in four-arm circle $(\mathrm{R}=30 \mathrm{~m})$

The 6 most significant conclusions of our results are as follows:

1. The results show that the capacity improvement does not follow the increase of the size of the circle. It means instead of building large circles better to increase the number of lanes; 
2. Leg by leg control can be a good solution in most of the cases since it provides high traffic performance even applying with a smaller radius (see Fig. 11);

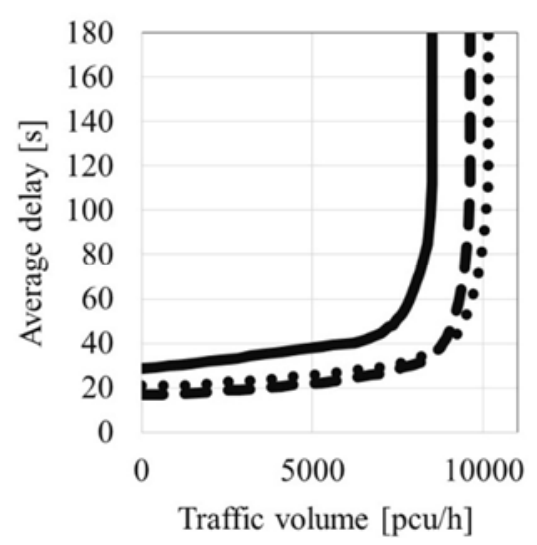

Fig. 13. Delay in four-arm circle $(\mathrm{R}=40 \mathrm{~m})$

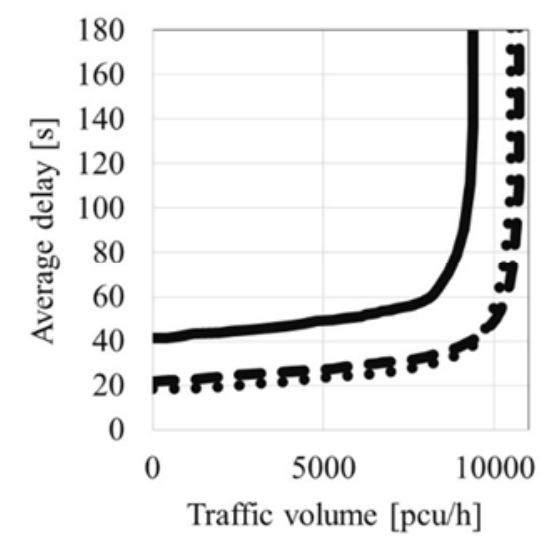

Fig. 15. Delay in four-arm circle $(\mathrm{R}=60 \mathrm{~m})$

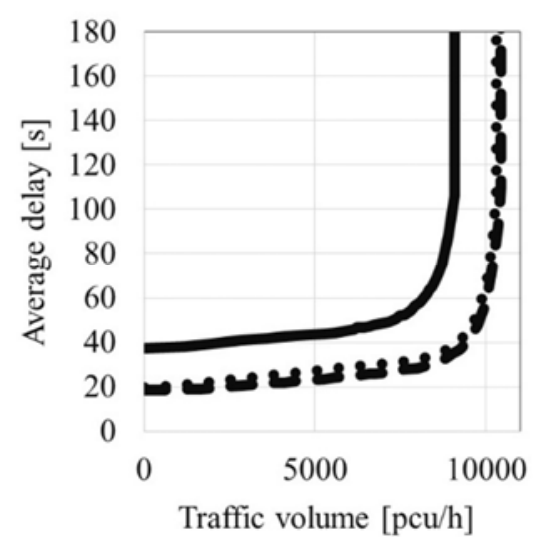

Fig. 14. Delay in four-arm circle $(\mathrm{R}=50 \mathrm{~m})$

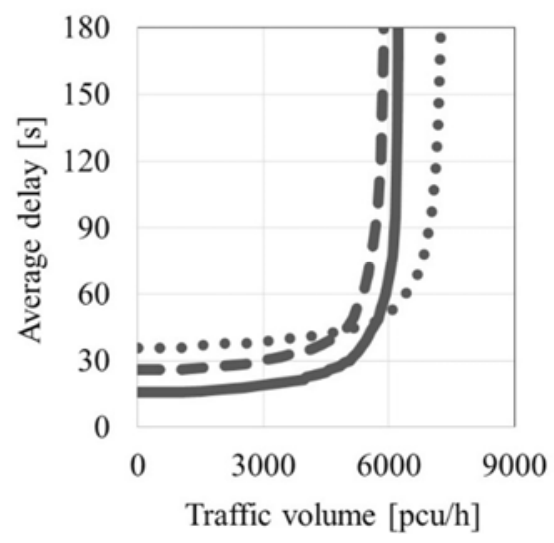

Fig. 16. Delay in five-arm circle $(\mathrm{L}=20 \mathrm{~m})$

3. In case there are more than four-arms, performance does not increase with size: capacity difference reaches only $\sim 300 \mathrm{pcu} / \mathrm{h}$ between the smallest and the almost five times bigger largest five-arm intersection, while the basic delay increased from $\sim 37 \mathrm{sec}$ to $\sim 65 \mathrm{sec}$ (see Fig. 16 and Fig. 20). This is significantly higher than the other programs', meaning that leg by leg control combined with five or more arms can be effective only in small sizes and in peak-hours;

4. Two phase control fits best for four-arm intersection. The performance of this program increases with size (see from Fig. 11 to Fig. 15). If there is no high demand for left turn movement, even applied with small size can be good. Since its signal plan similar to signal plans of the conventional intersections it is less 
complicated to coordinate it with other signalized intersections. In case of fivearms this program has lower capacity combined with high basic delay caused by the long cycle time of the complicated signal plan (see Fig. 16 to Fig. 20);

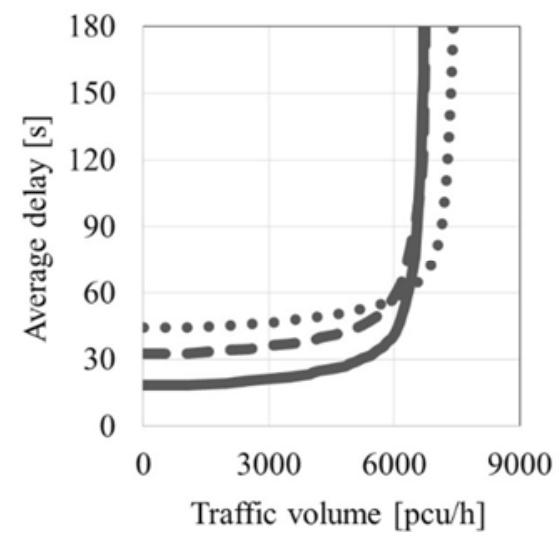

Fig. 17. Delay in five-arm circle $(\mathrm{L}=30 \mathrm{~m})$

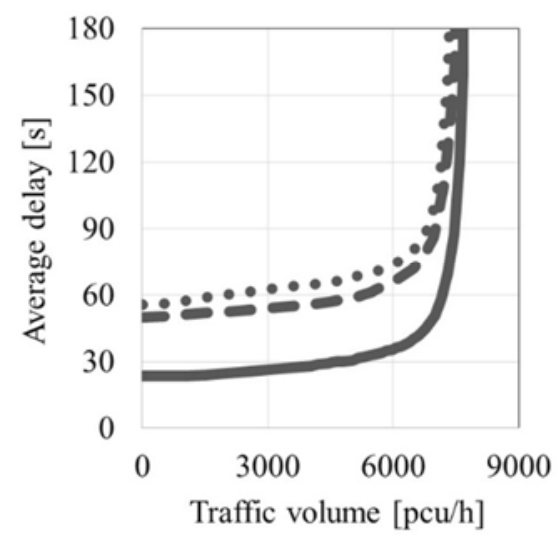

Fig. 19. Delay in five-arm circle $(\mathrm{L}=50 \mathrm{~m})$

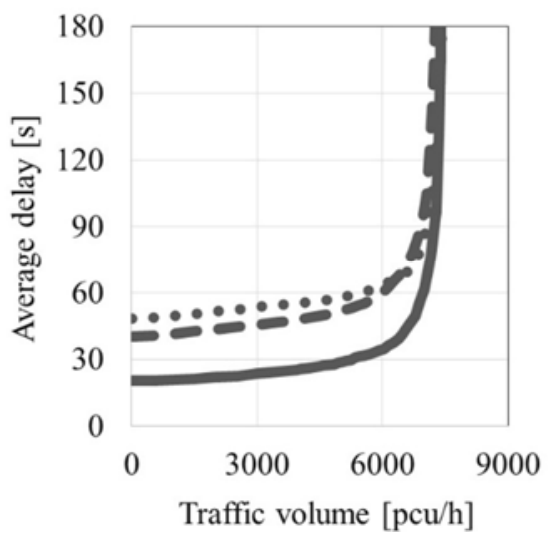

Fig. 18. Delay in five-arm circle $(\mathrm{L}=40 \mathrm{~m})$

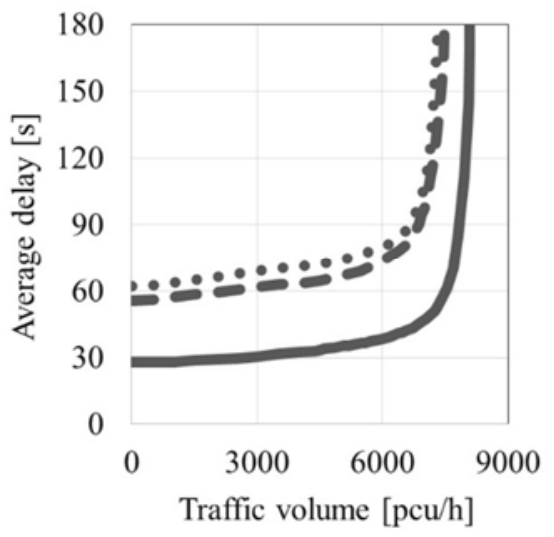

Fig. 20. Delay in five-arm circle $(\mathrm{L}=60 \mathrm{~m})$

5. All legs control provides great performance combined with large five-arm circles. The program of the largest circle provides half the delay than the other two programs while the capacity is $\sim 8 \%$ higher (see Fig. 20 );

6. On the other hand, in four-arms cases, where spiral geometry was applied, the all legs control cannot reach the performance of the other two control programs (see Fig.15). It is the effect of the high leaving time caused by the necessary time offsets, so the signal plan cannot provide enough green time to the cycle time. The four-arm circles with spiral geometry operate with high basic delays 
and low capacity, therefore the all legs control isn't recommended for spiral geometry, where more than one lane merging.

Another important parameter of traffic performance is saturation flow, which can be calculated using the number of lanes, sum of green times and maximum number of passing cars in one hour (the maximum number means the traffic volume with delay that exceeds the length of cycle time). The average value was $\sim 2330 \mathrm{pcu} / \mathrm{h}$ considering all examined junctions (see Fig. 21).

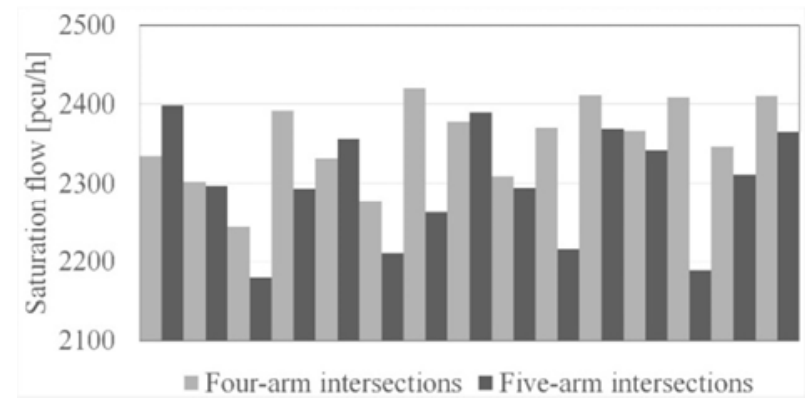

Fig. 21. The saturation flow in the examined junctions

This value is $\sim 26 \%$ higher than the basic $1850 \mathrm{pcu} / \mathrm{h}$ commonly used by the Hungarian practice to evaluate the traffic performance of conventional signalized intersections. It means that in some cases the same capacity can be provided by a signalized circular intersection with fewer lanes or lower delays than by a conventional signalized intersection.

\section{Conclusion}

Signal plans of the traffic signals in circular intersections are fundamentally different from the timing plans of conventional signalized intersections since they do not depend from the traffic volumes but parameters of the geometry given/planned. Modified timing plans are important to examine further because they can provide good solution if the original plans based on the geometric features are not adequate. The large signalized circular intersections have limited network applicability as coordination with other signalized intersections can be difficult and a multi-lane circles need larger space than a conventional intersection. In return, this unique type of intersection provides high operation performance and the highest reachable capacity among the at-grade junctions.

\section{Acknowledgements}

Authors would like to thank to PTV Group for the research license of VISSIM microsimulation software. 


\section{References}

[1] Hallworth M. S. Signalling roundabouts, Traffic Engineering \& Control, Vol. 33, No. 6, 1992, pp. 354-363.

[2] Stevens C. R. Signals and meters at roundabouts, in Mid-Continent Transportation Research Symposium, Ames, Iowa, August 18-19 2005, pp. 1-13, http://www.ctre. iastate.edu/pubs/midcon2005/StevensRoundabouts.pdf, (last visited 30 december 2015).

[3] Brilon W. Roundabouts: a state of art in Germany, 4th International Roundabout Conference, TRB 2014, Seattle, USA, 16-18 April 2014, pp. 1-15, http://teachamerica.com/ RAB14/RAB14papers/RAB14ppr045_Brilon.pdf (last visited 30 December 2015).

[4] Azhar A., Svante B. Signal control of roundabouts, Procedia - Social and Behavioral Sciences, Vol. 16, 2011, pp. 729-738.

[5] Maklári J. Adaptive traffic controlled roundabouts, in European Transport Conference, Cambridge, United Kingdom, 9 September 2002, pp. 1-33, http://abstracts.aetransport.org/ paper/index/id/1396/confid/8, (last visited 30 December 2015).

[6] Hungarian Road Society, ÚT 2-1.219:2009 - Planning, placing and operating of traffic signal control (in Hungarian), Technical Specification, (in Hungarian) 2009.

[7] Hoek R. R. M. Signalized turbo roundabouts; A study into the applicability of traffic signals on turbo roundabouts, Master Thesis at Delft University of Technology, 2013.

[8] Fortuijn L. G. H. Robustness of roundabout metering systems (RMS), 4th International Roundabout Conference, TRB 2014, Seattle, USA, 16-18 April 2014, http://repository. tudelft.nl/islandora/object/uuid:fcca8062-86ba-406a-833c-bad4627bb8bd?collection= research (last visited 30 December 2015).

[9] Maklári, J. Applicability questions of circle-shaped intersections equipped with traffic lights - Examples from other countries, (in Hungarian), Városi Közlekedés, Vol. 42, No. 4, 2002, pp. 216-231.

[10] Maklári J. Signal plans of circle-shaped intersection equipped with traffic lights, Part II, (in Hungarian), Városi Közlekedés, Vol. 42, No. 3, 2002, pp. 137-148.

[11] Tracz M., Chodur J. Performance and safety of roundabouts with traffic signals, Procedia Social and Behavioral Sciences, Vol. 53, 2012, pp. 789-800.

[12] Ma W., Liu Y., Head L., Yang X. Integrated optimization of lane markings and timings for signalized roundabouts, Transportation Research, Part C, Emerging Technologies, Vol. 36, 2013, pp 307-323.

[13] Ma W., Xie H., Bai Y., Zhao J., Yang X. Signal timing optimization model based on dualring phase scheme for roundabout, Journal of Central South University, Volume 20, No. 2 , 2013, pp 563-571.

[14] Bai Y., Chen W., Xue K. Association of signal-controlled method at roundabout and delay, Journal of Software, Vol. 7, No. 2, 2012, pp. 346-351.

[15] PTV Group, PTV VISSIM 7 User Manual, Karlsruhe, Germany, 2014.

[16] Vasvári G. Volume-delay functions of minor junctions created by microsimulation, Pollack Periodica, Vol. 9, No. 1, 2014, pp. 29-40.

[17] Kollár A. The supervision of passanger car unit values in different types of urban junctions with VISSIM program, Pollack Periodica, Vol. 9, No. 1, 2014, pp. 49-60.

[18] Kollár A. Analyses of vehicle delays at urban and rural road sections, Pollack Periodica, Vol. 9, No. 3, 2014, pp. 15-22. 